\title{
NADPH Oxidase Is Required for the Sensory Plasticity of the Carotid Body by Chronic Intermittent Hypoxia
}

\author{
Y.-J. Peng, ${ }^{1}$ J. Nanduri, ${ }^{1}$ G. Yuan, ${ }^{1}$ N. Wang, ${ }^{1}$ E. Deneris, ${ }^{3}$ S. Pendyala, ${ }^{2}$ V. Natarajan, ${ }^{2}$ G. K. Kumar, ${ }^{1}$ and N. R. Prabhakar ${ }^{1}$ \\ ${ }^{1}$ Center for Systems Biology of Oxygen Sensing and ${ }^{2}$ Division of Pulmonary and Critical Care Medicine, Department of Medicine, University of Chicago, \\ Chicago, Illinois 60637, and 3Department of Neuroscience, School of Medicine, Case Western Reserve University, Cleveland, Ohio 44106
}

Respiratory motoneuron response to hypoxia is reflex in nature and carotid body sensory receptor constitutes the afferent limb of this reflex. Recent studies showed that repetitive exposures to hypoxia evokes long term facilitation of sensory nerve discharge (sLTF) of the carotid body in rodents exposed to chronic intermittent hypoxia $(\mathrm{CIH})$. Although studies with anti-oxidants suggested the involvement of reactive oxygen species (ROS)-mediated signaling in eliciting SLTF, the source of and the mechanisms associated with ROS generation have not yet been investigated. We tested the hypothesis that ROS generated by NADPH oxidase (NOX) mediate CIH-evoked sLTF. Experiments were performed on ex vivo carotid bodies from rats and mice exposed either to $10 \mathrm{~d}$ of $\mathrm{CIH}$ or normoxia. Acute repetitive hypoxia evoked a $\sim 12$-fold increase in NOX activity in CIH but not in control carotid bodies, and this effect was associated with upregulation of NOX2 mRNA and protein, which was primarily localized to glomus cells of the carotid body. sLTF was prevented by NOX inhibitors and was absent in mice deficient in NOX2. NOX activation by CIH required 5-HT release and activation of 5- $\mathrm{HT}_{2}$ receptors coupled to PKC signaling. Studies with ROS scavengers revealed that $\mathrm{H}_{2} \mathrm{O}_{2}$ generated from $\mathrm{O}_{2}{ }^{-}$contributes to sLTF. Priming with $\mathrm{H}_{2} \mathrm{O}_{2}$ elicited sLTF of carotid bodies from normoxic control rats and mice, similar to that seen in $\mathrm{CIH}$-treated animals. These observations reveal a novel role for NOX-induced ROS signaling in mediating sensory plasticity of the carotid body.

\section{Introduction}

Repetitive exposures to hypoxia result in long-lasting activation of respiratory motor output known as long-term facilitation (LTF) of breathing (for review, see Powell et al., 1998). LTF is regarded as a form of plasticity of respiratory motoneuron activity that is uniquely expressed in response to repetitive but not by continuous hypoxia (Baker et al., 2001). Respiratory motoneuron response to hypoxia is reflex in nature and carotid body sensory receptor constitutes the afferent limb of this reflex. Recent studies from our laboratory showed that repetitive hypoxia also induces LTF of the carotid body afferent nerve activity [sensory LTF (sLTF)] (Peng et al., 2003, 2006b). However, unlike LTF of the respiratory motor activity, sLTF of the carotid body requires prior conditioning with chronic intermittent hypoxia (CIH). The CIH-induced sLTF was reversible after reexposure to normoxia and could be prevented by treating $\mathrm{CIH}$ rats with antioxidants (Peng et al., 2003), indicating the involvement of reactive oxygen species (ROS). However, neither the source nor the mechanism(s) by which ROS are generated in $\mathrm{CIH}$-treated carotid bodies has been examined.

The family of NADPH oxidase (NOX) enzymes constitutes

Received 0ct. 3, 2008; revised Nov. 15, 2008; accepted Feb. $28,2009$.

This work was supported by National Institutes of Health-National, Heart, Lung, and Blood Institute Grants HL-90554, HL-76537, HL-86493 (N.R.P.), and HL-08533 (V.N.). We are grateful to Dr. D. J. Lambeth (Department of Pathology, Emory University School of Medicine, Atlanta, GA) for the generous gift of NOX4 antibody.

Correspondence should be addressed to Nanduri R. Prabhakar, Center for Systems Biology of Oxygen Sensing, Department of Medicine, The University of Chicago, 5841 S. Maryland Avenue, MC 5068, Chicago, IL 60637. E-mail: nprabhak@medicine.bsd.uchicago.edu.

DOI:10.1523/JNEUROSCI.4768-08.2009

Copyright $\odot 2009$ Society for Neuroscience $\quad$ 0270-6474/09/294903-08\$15.00/0 one of the major sources of ROS generation. NOX2 (also called gp91 ${ }^{\text {phox }}$ ) is the most extensively studied member of the NOX family. Recent studies have shown that ROS generated by NOX2 mediate long-term potentiation (LTP) of neuronal activity, hippocampal synaptic plasticity, and memory (Kishida et al. 2006; Kishida and Klann, 2007). Zhan et al. (2005) reported that NOX2 mediates $\mathrm{CIH}$-induced changes in sleep behavior. NOX2 is expressed in glomus cells (the putative hypoxic sensing cells) of the carotid body (Youngson et al. 1997; Dinger et al., 2007) and contributes to the induction of LTP elsewhere in the nervous system (Kishida et al. 2006); these findings prompted us to hypothesize that NOX2 and/or closely related NOX isoform mediate sLTF of the carotid body. Here, we demonstrate that $\mathrm{CIH}$ leads to regulated NOX2 activation that requires $5-\mathrm{HT} / 5-\mathrm{HT}_{2}$ receptors/protein kinase $\mathrm{C}$ (PKC) signaling and the resulting ROS, especially $\mathrm{H}_{2} \mathrm{O}_{2}$ is critical for evoking sLTF. These observations unravel a novel role for NOX2 and ROS in inducing sensory plasticity of the carotid body.

\section{Materials and Methods}

Experiments were approved by the Institutional Animal Care and Use Committee of the University of Chicago and were performed on adult male rats (Sprague Dawley, 200-300 gm), wild type (WT, C57BL/6), hemizygous $g p 91^{\text {phox }-/ Y}$ (from Jackson Laboratories; weights 20-25 gm), and Pet-1 ${ }^{-1-}$ mice (from Dr. Deneris, weights $20-25 \mathrm{gm}$ ).

Exposure to chronic intermittent hypoxia. Unrestrained, freely moving animals housed in feeding cages were exposed to chronic intermittent hypoxia $\left(\mathrm{CIH}\right.$; for $10 \mathrm{~d} ; 8 \mathrm{~h} \cdot$ day $^{-1}$ ) as previously described (Peng and Prabhakar, 2004). Briefly, animals were placed in a specialized chamber, which was flushed with alternating cycles of pure nitrogen and compressed air. During hypoxia, inspired $\mathrm{O}_{2}$ levels reached $5 \% \mathrm{O}_{2}$ (nadir). 
The gas flows were regulated by timercontrolled solenoid valves. Ambient $\mathrm{O}_{2}$ and $\mathrm{CO}_{2}$ levels in the chamber were continuously monitored by an $\mathrm{O}_{2} / \mathrm{CO}_{2}$ analyzer (Alpha Omega Instrument; Series 9500). Control experiments were performed on animals exposed to alternating cycles of compressed room air instead of hypoxia in the same chamber. Acute experiments were performed on rats or mice anesthetized with intraperitoneal injections of urethane $\left(1.2 \mathrm{~g} \cdot \mathrm{kg}^{-1}\right.$, Sigma $) \sim 16 \mathrm{~h}$ after terminating $\mathrm{CIH}$.

Measurements of carotid body sensory activity. Sensory activity from carotid bodies ex vivo was recorded as described previously (Peng and Prabhakar 2004, Peng et al. 2006b). Briefly, carotid bodies along with the sinus nerves were harvested from anesthetized animals. After cleaning the connective tissue, the carotid body along with the sinus nerve was placed in a recording chamber (volume $250 \mu \mathrm{l}$ ) and superfused at a rate of $2 \mathrm{ml} \cdot \mathrm{min}^{-1}$ with warm physiological saline $\left(36^{\circ} \mathrm{C}\right)$ containing the following (mM): $\mathrm{NaCl}$ (125), $\mathrm{KCl}(5), \mathrm{CaCl}_{2}$ (1.8), $\mathrm{MgSO}_{4}$ (2), $\mathrm{NaH}_{2} \mathrm{PO}_{4}$ (1.2), $\mathrm{NaHCO}_{3}$ (25), D-Glucose (10), Sucrose (5), bubbled with $95 \% \mathrm{O}_{2} / 5 \%$ $\mathrm{CO}_{2}, \mathrm{pH}$ 7.4. To facilitate recording of clearly identifiable action potentials, the sinus nerve was treated with $0.1 \%$ collagenase for $5 \mathrm{~min}$. Action potentials (2-4 active units) were recorded from one of the nerve bundles with a suction electrode, amplified (AC-preamplifier, Grass Instrument, P511K; bandwidth of $100-$ $3000 \mathrm{~Hz}$ ), displayed on an oscilloscope (Tektronix $5 \mathrm{~B} 12 \mathrm{~N})$, and stored in a computer via an A/D translation board (PowerLab/8P, AD Instruments). "Single" units were selected based on the height and duration of the individual action potentials using a spike discrimination program (Spike Histogram Program, Power Lab, AD Instruments). In each carotid body, at least 2 chemoreceptor units were analyzed.

Induction of SLTF of the carotid body. The protocols for evoking SLTF of rat carotid body ex vivo were the same as described previously (Peng et al. 2003). Briefly, baseline sensory activity was recorded for 15 min with perfusate $\left(\mathrm{pO}_{2}=\sim 140 \mathrm{mmHg}\right.$ ) containing either vehicle or the drugs followed by 10 episodes of repetitive hypoxia $\left(\mathrm{pO}_{2}=\sim 42 \mathrm{mmHg}\right.$ for $30 \mathrm{~s}$ ), separated by $5 \mathrm{~min}$ of normoxia $\left(\mathrm{pO}_{2}=\sim 140 \mathrm{mmHg}\right.$ ). Sensory activity was monitored continuously for $60 \mathrm{~min}$ after terminating repetitive hypoxia. The protocols evoking SLTF in mice carotid body ex vivo were the same except that 5 episodes of repetitive hypoxia were used.

Measurements of NADPH oxidase activity. NADPH oxidase activity was determined by monitoring $\mathrm{O}_{2} \cdot{ }^{-}$dependent reduction of ferric cytochrome C at $550 \mathrm{~nm}$ as described previously (Mayo and Curnutte, 1990). Briefly, freshly harvested carotid bodies were placed in PBS, $0.9 \mathrm{~mm}$ $\mathrm{CaCl}_{2}, 0.5 \mathrm{~mm} \mathrm{MgCl}_{2}$ and $7.5 \mathrm{~mm}$ glucose, $\mathrm{pH}$ 7.4. The reaction was initiated by addition of cytochrome $\mathrm{C}(75 \mu \mathrm{M})$ to the reaction medium. Increase in the absorbance was monitored at $550 \mathrm{~nm}$ for $5 \mathrm{~min}$. The amount of reduced cytochrome $\mathrm{C}$ formed during the reaction was determined using the molar extinction coefficient of $21.7 \mu$ moles $\cdot \mathrm{cm}^{-2}$. The enzyme activity was expressed as picomoles $\min ^{-1}$ per carotid body.

NOX mRNA expression in the carotid body by quantitative real-time PCR. Real-time RT-PCR was performed using a MiniOpticon system (Bio-Rad Laboratories) with SYBR GreenER two-step qRT-PCR kit (\#11764-100, Invitrogen). Briefly, RNA was extracted from rat carotid bodies using TRIZOL and was reverse transcribed using superscript III reverse transcriptase. Primer sequences for real time RT-PCR amplification were as follows: $18 \mathrm{~s}$ : [forward (fw)] GTAACCCGTTGAAC-
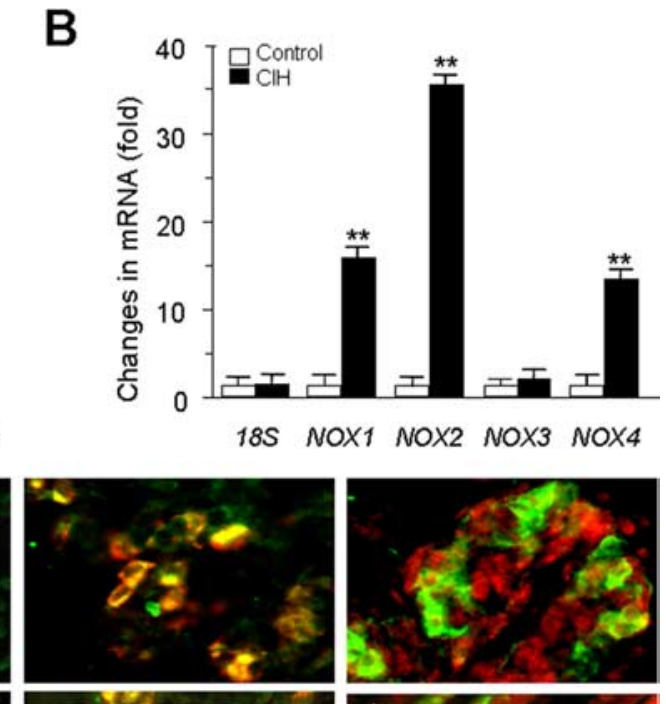

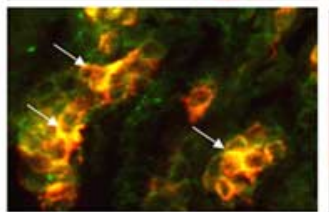

NOX $2+$ CGA
NOX4+TH

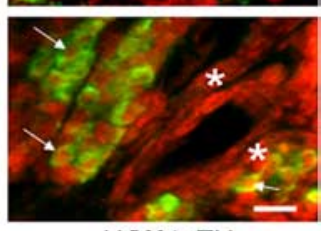

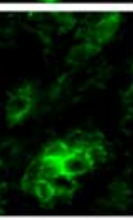

NOX2+CGA

Figure 1. CIH upregulates NOX enzyme activity, mRNAs in rat carotid body. $A$, Effect of repetitive hypoxia on NOX activity.

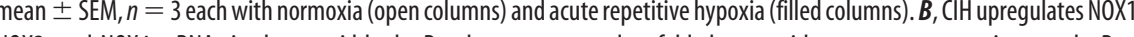
, and NOX4 mRNAs in the carotid body. Results are expressed as fold change with respect to normoxic controls. Data

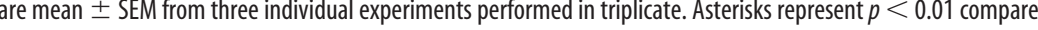
be seen in glomus cells (stained with tyrosine hydroxylase; TH; green color; denoted by arrows) as well as other cells (shown with *). Scale bar, $20 \mu \mathrm{m}$. CON, Control.
CCCATT and [reverse (rev)] CCATCCAATCGGTAGTAGCG (Size 151, Gene Bank \# X_01117); NOX1: (fw) CACTGTGGCTTTGGTTCTA and (rev) TGAGGACTCCTGCAACTCCT (Size 240, Gene Bank \# NM_053683); NOX2: (fw) GTGGAGTGGTGTGAATGC and (rev) TTTGGTGGAGGATGTGATGA (Size 219, Gene Bank \# NM_023965); NOX3: (fw) GACCCAACTGGAATGAGGAA and (rev) AATGAACGACCCTAGGATCT (Size 150, Gene Bank \# NM_001004216); and NOX4: (fw) CGGGGTGGCTTGTTGAAGTAT and (rev) CGGGGTGGCTTGTTGAAGTAT (Size 205, Gene Bank \# NM_053524). Relative mRNA quantification was calculated using the comparative threshold

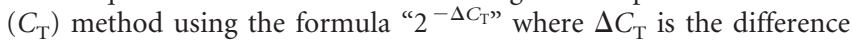
between the threshold cycle of the given target cDNA between nomoxia and $\mathrm{CIH}$. The $C_{\mathrm{T}}$ value was taken as a fractional cycle number at which the emitted fluorescence of the sample passes a fixed threshold above the baseline. Values were compared with an internal standard gene 18S. Purity and specificity of all products were confirmed by omitting the template and by performing a standard melting curve analysis.

Immunohistochemistry. Anesthetized rats or mice were perfused intracardially with heparinized phosphate buffered saline (PBS; pH 7.4) at a rate of $10 \mathrm{ml} \mathrm{min}^{-1}$ for $10 \mathrm{~min}$ followed by buffered Formalde $(10 \%$ Formalin; Fischer Scientific). Carotid artery bifurcations were removed and placed in $4 \%$ paraformaldehyde-PBS for $1 \mathrm{~h}$ at $4^{\circ} \mathrm{C}$, washed in PBS, and cryoprotected in $30 \%$ sucrose-PBS at $4^{\circ} \mathrm{C}$ for $24 \mathrm{~h}$. Specimens were frozen in Tissue Tek (OCT; VWR Scientific) and serially sectioned at 8 $\mu \mathrm{m}$. For NOX2 and NOX4 localization, rat carotid body sections were incubated at $37^{\circ} \mathrm{C}$ for $2 \mathrm{~h}$ with either anti-NOX2 antibody (Santa Cruz, \# 

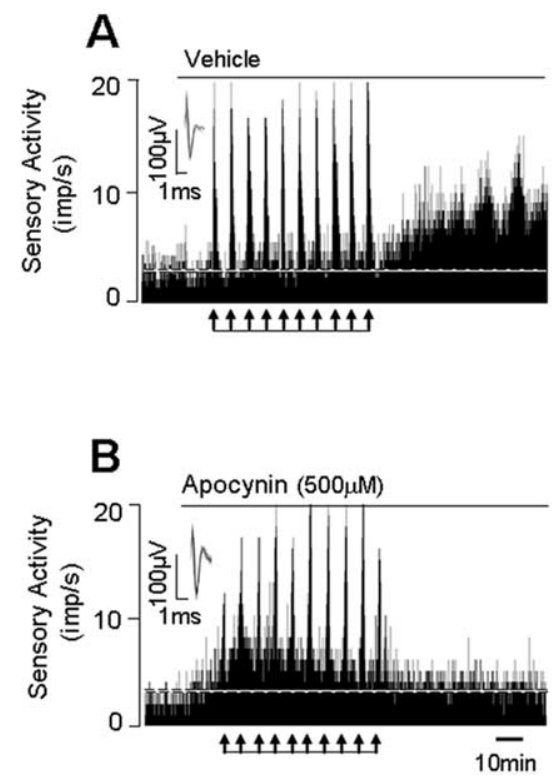

Figure 2. NOX inhibitors prevent SLTF of the rat carotid body. $\boldsymbol{A}, \boldsymbol{B}$, Examples of repetitive hypoxia-evoked SLTF of CIH-treated rat carotid bodies in the presence of vehicle $(\boldsymbol{A})$ or apocynin $(\boldsymbol{B})$. Arrows in $\boldsymbol{A}$ and $\boldsymbol{B}$ denote application of repetitive hypoxia. Superimposed action potentials of a single fiber from which the data were derived are shown in the insets. imp, Impulses. $C$, Average data of the effects of apocynin (500 $\mu \mathrm{M})$, AEBFS $(500 \mu \mathrm{M}$ ), and diphenyl iodinium (DPI; $3 \mu \mathrm{M})$ on sLTF (sensory activity averaged during 60 min postrepetitive hypoxia period). Data presented are mean \pm SEM from six experiments in each group. Asterisk denotes $p<0.05$ compared with CIH-exposed carotid bodies treated with vehicle.

A

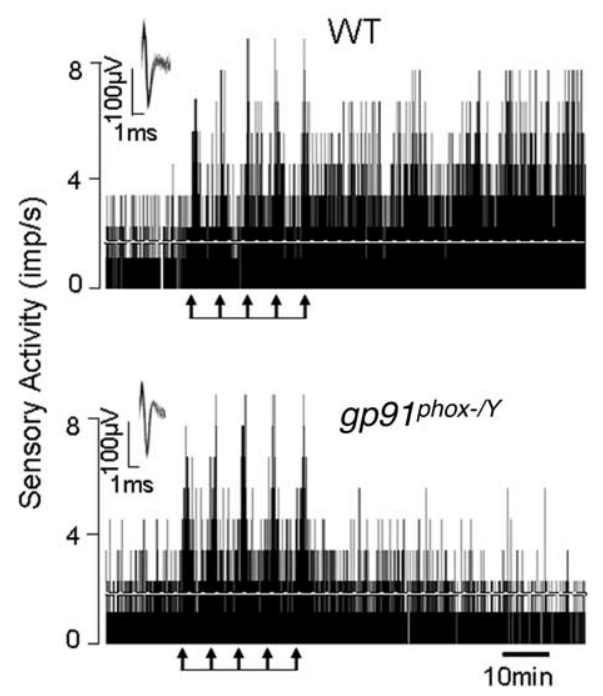

B

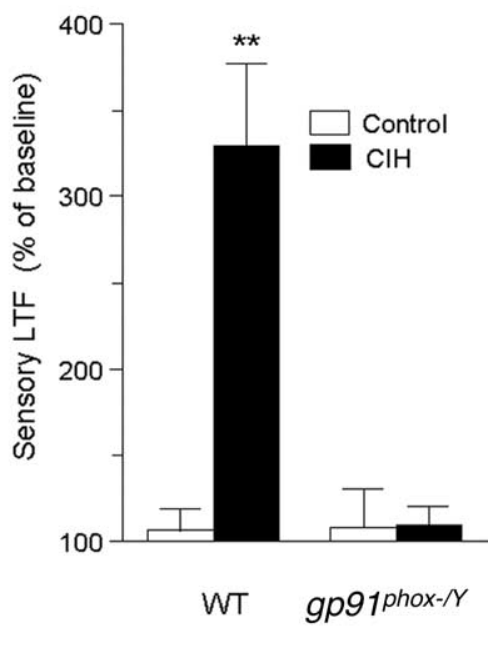

Figure 3. Absence of sLTF of the carotid body in $g p 91^{p h o x-/ Y}$ mice exposed to CIH. $A$, Examples of repetitive hypoxia-evoked sLTF of carotid bodies from CIH-treated WT (top) and $g p 91^{\text {phox- }}$ (bottom) mice. Arrows denote application of repetitive hypoxia. Superimposed action potentials of a single fiber from which the data were derived are shown in the insets. imp, Impulses. $\boldsymbol{B}$, Average data showing the magnitude of sLTF of the carotid body from WT and $g p 91^{\text {phox }-/ Y}$ mice exposed to either normoxia (control, open columns) or CIH (filled columns). Data presented are mean \pm SEM from WT (control and CIH, $n=7$ each) and gp $91^{\text {phox }-/ Y}$ (control and $\mathrm{ClH}, n=7$ each) mice. Asterisks denote $p<0.01$ compared with control carotid body.

s.c.-5827;1:50) or anti-NOX4 antibody (from Dr. D. Lambeth; 1:500 dilution) followed by FITC and Alexa Fluor 555 conjugated secondary antibodies (Invitrogen). For identification of glomus cells, sections were doubled stained with polyclonal anti-chromogranin-A (CGA) antibody (Abcam, \# ab45138; 1:100) or monoclonal anti-tyrosine hydroxylase (TH) antibody (Sigma; 1:4000), established markers of glomus cells. In mice, 5-HT immunolocalization in the carotid body was performed with monoclonal anti-5-HT antibody (Millipore; 1:100). Sections were mounted in DAPIcontaining media and visualized using a Nikon fluorescent microscope.

Immunoblot assays. Immunoblot assays were performed as described previously (Yuan et al. 2008). Briefly, carotid bodies were homogenized in RIPA buffer $(1 \times$ PBS, $1 \%$ Nonidet P-40, $0.5 \%$ sodium deoxycholate, $0.1 \%$ SDS, 1 mM sodium orthovanadate, $0.1 \mathrm{~mm}$ PMSF, $5 \mu \mathrm{g}$ $\mathrm{ml}^{-1}$ leupeptin, $5 \mu \mathrm{g} \mathrm{ml}^{-1}$ aproteinin, and 10 $\mu \mathrm{l} \cdot \mathrm{ml}^{-1}$ protease inhibitor cocktail). Cell lysates were fractionated by $7.5 \%$ polyacrylamide-SDS gel electrophoresis and transferred to a polyvinylpyrrolidone difluoride membrane (Immobilon-P, Millipore). The membrane was blocked with Tris-buffered saline (TBS-T) containing $5 \%$ nonfat milk at $4^{\circ} \mathrm{C}$ overnight. Membranes were incubated with anti-gp91 ${ }^{\text {phox }}$ antibody (Santa Cruz; 1:200) or anti-NOX4 antibody (from Dr. Lambeth; 1;500) or anti-phosphoMARCKS antibody (Protein Tech Group; 1:1000 dilution) or anti- $\alpha$-tubulin antibody (Sigma; $1: 1000$ ) in TBS-T containing 3\% nonfat milk. Membranes were treated with donkey anti-goat secondary antibody conjugated with horseradish peroxidase (Santa Cruz; 1:2000) in TBS-T containing 3\% nonfat milk. Immune complexes on the membrane were visualized using a chemiluminescence (ECL) detection system (Amersham). The membranes were exposed to Kodak XAR films.

Measurement of 5-hydroxytryptamine release. 5-Hydroxytryptamine (5-HT) release from carotid bodies was analyzed by high performance liquid chromatography coupled to an electrochemical detection system (HPLC-ECD) as described previously (Jacono et al., 2005). Briefly, freshly isolated carotid bodies were incubated with $200 \mu \mathrm{l}$ of $\mathrm{Ca}^{2+} / \mathrm{Mg}^{2+}$ free Krebs-Ringer bicarbonate (KRB) medium preequilibrated with $95 \% \mathrm{O}_{2}+5 \% \mathrm{CO}_{2}$ for $90 \mathrm{~min}$ at $4^{\circ} \mathrm{C}$. Subsequently, incubation medium was switched to $50 \mu \mathrm{l}$ of $\mathrm{KRB}$ with $\mathrm{Ca}^{2+} / \mathrm{Mg}^{2+}$ equilibrated with appropriate gas mixtures resulting in medium $\mathrm{PO}_{2}$ s of either $146 \pm 7$ $\mathrm{mmHg}$ (normoxia) or $43 \pm 8 \mathrm{mmHg}$ (hypoxia). Each gas challenge was given for $5 \mathrm{~min}$. $5-\mathrm{HT}$ in the medium was analyzed by HPLCECD and expressed as femtomoles of $5-\mathrm{HT} \cdot \min ^{-1} \cdot$ carotid body $^{-1}$.

Experimental protocols. Series 1: In these experiments, the effects of $\mathrm{CIH}$ on NOX enzyme activity, mRNAs encoding various NOX isoforms and NOX protein expressions were analyzed in the rat carotid bodies. Control experiments were performed on rats reared under normoxia ( $n=6$ each; 6 carotid bodies/experiment). For measurements of NOX enzyme activity, carotid bodies were challenged with 10 episodes of repetitive hypoxia $\left(\mathrm{pO}_{2}=\sim 42\right.$ $\mathrm{mmHg}$ for $30 \mathrm{~s}$. followed by $5 \mathrm{~min}$. of normoxia $\mathrm{pO}_{2}=\sim 140 \mathrm{mmHg}$ ). Ten minutes after terminating the $10^{\text {th }}$ episode of hypoxia, the carotid bodies were collected and the NOX activity was determined as described above. Series 2: The effects of NOX inhibitors, apocynin, diphenyl iodinium (DPI), 4-(2aminoethyl) benzenesulfonyl fluoride hydrochloride (AEBFS) on sLTF of the rat carotid body were examined (vehicle control; apocynin; DPI; AEBSF $n=6$ each). Series 3: sLTF was examined in wild type (WT) and 
$g p 91^{\text {phox }-/ Y}$ mice exposed either to normoxia or CIH (WT and $g p 91^{\text {phox }-/ Y}, n=7$ each). Series 4 : Carotid bodies were harvested from $\mathrm{CIH}-$ and normoxia-exposed rats and the effects of acute hypoxia on 5-HT release were examined (control and $\mathrm{CIH} ; n=3$ each and 6 carotid bodies per experiment). Series 5: sLTF of carotid bodies was examined in WT and Pet-1 $1^{-1-}$ mice exposed either to normoxia or $\mathrm{CIH}$ ( $n=7$ each for WT and Pet-1 ${ }^{-1-}$ mice). Series 6: The effects of ketanserin, a 5-HT-2 receptor antagonist or bisindolylmaleimide-1 (Bis-1), a PKC inhibitor on repetitive hypoxia-evoked pMARCKS expression ( $n=3$; six carotid bodies/experiment) and $\operatorname{sLTF}(n=6)$ were analyzed in carotid bodies harvested from normoxia- and $\mathrm{CIH}$-exposed rats. Series 7: The effects of MnTMPyP $(n=6)$, a membrane permeable scavenger of $\mathrm{O}_{2}{ }^{-}$, , or PEG-catalase $(n=6)$, a scavenger of $\mathrm{H}_{2} \mathrm{O}_{2}$, on sLTF were examined. Series 8: The effects of exogenous administration of $\mathrm{H}_{2} \mathrm{O}_{2}$ on sLTF were examined in rats reared under normoxia with $(n=7)$ and without $(n=6) \mathrm{H}_{2} \mathrm{O}_{2}$. In 5 additional rat carotid bodies, sensory activity was recorded for 90 min while superfusing carotid bodies with $500 \mathrm{nM} \mathrm{H}_{2} \mathrm{O}_{2}$. Parallel experiments were performed examining the effects of exogenous administration of $\mathrm{H}_{2} \mathrm{O}_{2}$ on carotid body sLTF in WT, $g p 91^{\text {phox- } / Y}$ and Pet- $1^{-1-}$ mice $(n=6-7$ each). Based on preliminary studies $200 \mathrm{nM} \mathrm{H}_{2} \mathrm{O}_{2}$ was chosen in the experiments involving mice carotid bodies.

Drugs and antibodies. The following drugs or chemicals were used: 4-(2-aminoethyl) benzenesulfonyl fluoride hydrochloride (AEBFS), 2-aminoethyl diphenylborinate (2-APB), apocynin (Acetovanillone), cadmium chloride, diphenyl iodinium (DPI), hydrogen peroxide, ketanserin tartrate, PEG-catalase, and phorbol 12-myristate 13-acetate (PMA) from Sigma; bisindolymadeimide I (Bis-1, Calbiochem); manganese (III) tetrakis (1-methyl-4-pyridyl) porphyrin pentachloride (MnTMPyP, Alexis Chemicals). Stock solutions were made fresh and desired concentrations of the drugs were added to the medium in the reservoirs before the experiment.

Data analysis. Chemoreceptor activity of "single units" (impulses $\cdot \mathrm{s}^{-1}$ ) was averaged every $15 \mathrm{~min}$ under baseline conditions, every $30 \mathrm{~s}$ during and every $5 \mathrm{~min}$ following acute hypoxia challenge for $60 \mathrm{~min}$. Changes in chemoreceptor activity were expressed as percentage of baseline values. The data are expressed as mean \pm SEM. Statistical significance was assessed by one-way ANOVA followed by Tukey's post hoc test. $p$ values $<0.05$ were considered significant.

\section{Results}

\section{Effects of CIH on NOX expression and enzyme activity in the} carotid body

Basal NOX activity was comparable between CIH- and normoxia-treated carotid bodies. Acute repetitive hypoxia resulted in $\sim 12$-fold increase in NOX activity in CIH but not in control carotid bodies $(p<0.01)$ (Fig. $1 A)$, and apocyanin $(500$ $\mu \mathrm{M})$, an inhibitor of NOX, prevented this response. Unlike repetitive exposures, a single episode of hypoxia was ineffective in activating $\operatorname{NOX}(p>0.05)$.

Several NOX isoforms have been identified [see Bedard and Krause (2007) for references]. To determine which of the NOX isoforms are expressed in the rat carotid body, and whether they are affected by $\mathrm{CIH}, \mathrm{NOX} 1,2,3$, and 4 mRNA expressions were examined by quantitative real time PCR in control and $\mathrm{CIH}$ treated carotid bodies. NOX1, 2, 3, and 4 mRNAs could readily be detected in the control carotid body (Fig. $1 B$ ). In CIH-treated
B

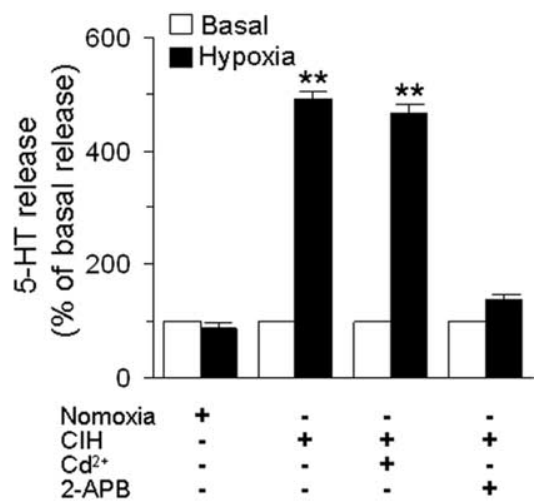

carotid bodies, NOX 1, 2 and 4 mRNAs were upregulated; whereas NOX3 mRNA expression was unaffected. The magnitude of increase in NOX2 mRNA was more pronounced $(\sim 35$ fold) than NOX 1 ( $\sim 16$-fold) and NOX4 ( $\sim 13$-fold $)$. Because NOX1 is a homolog of NOX2 (Suh et al. 1999; Bánfi et al. 2000), we chose to examine the localization of NOX2 and NOX4 proteins by immunohistochemistry in control and $\mathrm{CIH}$-treated carotid bodies. Immunoreactive product of NOX2 was localized to the cytoplasm of glomus cells; whereas that of NOX4 was localized to the nucleus of glomus as well as other cells in control and $\mathrm{CIH}$-treated carotid bodies (Fig. 1C,D). Western blot assay revealed a $\sim 2.0-2.5$-fold increase in NOX2 and NOX 4 proteins in $\mathrm{CIH}$ compared with control carotid bodies $(p<0.01)$.

\section{NOX is required for CIH-induced SLTF of the carotid body}

The effects of three structurally distinct inhibitors of NOX, i.e., apocynin, DPI and AEBFS on sLTF were examined to assess the potential contribution of NOX activation to sLTF. As shown Figure $2 A, B$, repetitive hypoxia evoked robust sLTF in CIH-exposed carotid bodies and apocynin prevented this effect. However, hypoxia-evoked sensory excitation $\left(\Delta\right.$ impulses $\left.\cdot \mathrm{s}^{-1}\right)$ was unaffected by apocynin $(\mathrm{CIH}+$ vehicle control $=+10.8 \pm 2.1$ vs $\mathrm{CIH}+$ apocynin $=+8.7 \pm 1.7 ; p>0.05)$. Like apocyanin, 3 $\mu \mathrm{M}$ DPI and $500 \mu \mathrm{M}$ AEBFS also prevented the induction of sLTF (Fig. 2C).

Although the above described effects of pharmacological inhibitors suggest a role for NOX in evoking sLTF, they cannot differentiate the contribution of different NOX isoforms. To assess the selective contribution of NOX2, sLTF was monitored in $\mathrm{CIH}$-exposed mice deficient in gp91 ${ }^{\text {phox }}$ i.e., NOX2 and age matched wild type (WT) controls. As shown in Figure 3, sLTF could be evoked in CIH-treated WT but not in $g p 91^{\text {phox-/Y }}$ mice. However, hypoxia-evoked sensory excitation could be elicited in both groups of mice (Fig. $3 A)(p>0.05)$. 
A
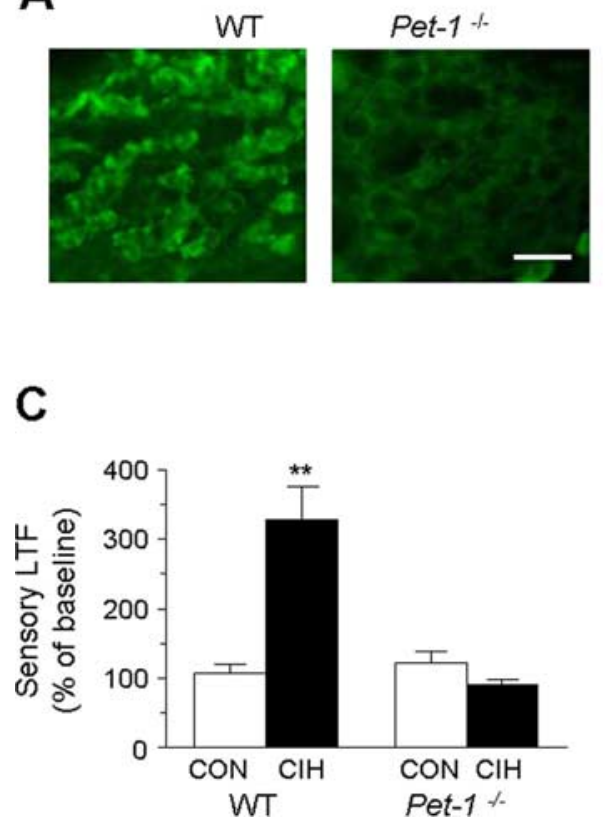

Figure 5. Absence of sLTF of the carotid body in Pet- $1^{-1-}$ mice with impaired 5-HT expression in glomus cells. A, 5-HT-like immunoreactivity in glomus cells of the carotid bodies from WT and Pet-1 ${ }^{-1-}$ mice. Note the absence of 5-HT-like immunoreactivity in the carotid body from Pet-1 ${ }^{-1-}$ mice. $B$, Representative tracings of the carotid body sensory response to repetitive hypoxia (at arrows) from WT (top two panels) and Pet- $1^{-1-}$ (bottom two panels) mice exposed to either normoxia (control) or ClH. Insets represent superimposed action potentials from a single unit. C, Average data of the magnitude of SLTF (sensory activity averaged during 60 min period of postrepetitive hypoxia) presented as percentage of baseline sensory activity (i.e., before 5 episodes of repetitive hypoxia). Data represent mean \pm SEM from WT (Control and CIH, $n=7$ each) and Pet- $1^{-1-}$ (Control and CIH, $n=7$ each) mice. Asterisks denote $p<0.01$ compared with control. Note the absence of SLTF in Pet- $1^{-1-}$ mice treated with $\mathrm{CIH}$.

\section{A}
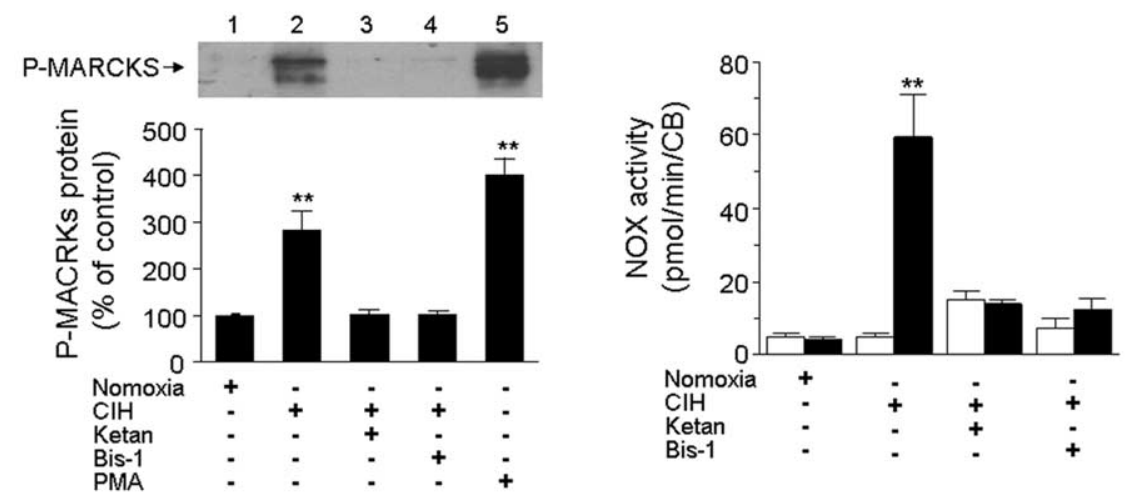

Figure 6. NOX activation by repetitive hypoxia in the $\mathrm{ClH}$-exposed rat carotid bodies requires activation of 5-HT2 receptors and PKC. $\boldsymbol{A}$, Acute repetitive hypoxia activates PKC via 5- $\mathrm{HT}_{2}$ receptors. The level of phosphorylation of MARCKS (P-MARCKS) was monitored in the rat carotid bodies by Western blot as an index of PKC activation. Top, example of the Western blot. Effect of repetitive hypoxia on P-MARCKS expression in carotid bodies from normoxia-treated control (lane 1), CIH exposed (lane 2), ClH-treated carotid bodies in presence of $1 \mu \mathrm{m}$ ketanserin (lane 3), or $1 \mu \mathrm{m}$ Bis-1 (lane 4) or $100 \mathrm{~nm}$ PMA (positive control; lane 5). Bottom, Average data of densitometric analysis presented as percentage of control. Note that repetitive hypoxia increased P-MARCKS expression in ClH but not in control carotid bodies, and this effect was prevented by ketanserin as well as Bis-1. B, Effect of repetitive hypoxia on NOX activation in the carotid bodies from normoxia and ClH-treated carotid bodies in the absence and presence of $1 \mu \mathrm{m}$ ketanserin or $1 \mu \mathrm{m}$ Bis-1. Note that ketanserin and Bis-1 prevent NOX activation by repetitive hypoxia in $\mathrm{ClH}$-exposed carotid bodies. Data presented in $\mathbf{A}$ and $\mathbf{B}$ represent mean \pm SEM from three individual experiments performed in triplicate. Asterisks represent $p<0.01$ compared with controls. Ketan, Ketanserin; CB, carotid bodies.

\section{CIH-evoked NOX activation and sLTF require 5-HT and $5-\mathrm{HT}_{2}$ receptors}

The following experiments were performed to address the mechanism(s) underlying NOX activation in CIH-treated carotid bod- ies. Exogenous applications of 5-HT has been shown to activate NOX in the carotid body via $5-\mathrm{HT}_{2}$ receptors coupled to protein kinase $\mathrm{C}$ (PKC) activation (Peng et al. 2006a). To examine the role of 5-HT in NOX activation, we first determined whether hypoxia releases 5-HT from carotid bodies. As shown in Figure 4, hypoxia ( $43 \pm 8 \mathrm{mmHg}$ ) resulted in robust 5-HT release from $\mathrm{CIH}$-treated carotid bodies (basal release during normoxia $=$ $1.6 \pm 0.08$ vs hypoxia $=8.1 \pm 0.1$ femtomoles per min per carotid body); whereas it had no effect on 5-HT release from normoxia-treated carotid body (Fig. 4B). The hypoxia-evoked 5-HT release from CIH-treated carotid body was completely prevented by $75 \mu \mathrm{M} 2$-APB, a purported ionositol phosphate-3 (IP3) receptor/ TRPM2 channel blocker (Pinilla et al. 2005). In contrast, $\mathrm{CdCl}_{2}(300 \mu \mathrm{M})$, a broad-spectrum voltage-gated $\mathrm{Ca}^{2+}$ channel blocker had no significant effect (Fig. 4B).

If 5-HT is the upstream signaling molecule for CIH-evoked NOX activation, then the ensuing sLTF should be absent in carotid bodies with impaired 5-HT expression. Mice deficient in the gene encoding the Pet-1 transcription factor exhibit markedly reduced 5-HT expression in the CNS (Hendricks et al. 1999, 2003) and Pet- $1^{-1-}$ mice offer elegant model for exploring the role of 5-HT in CIH-evoked sLTF. We first examined whether 5-HT expression is reduced in the carotid bodies of Pet- $1^{-/-}$mice. As shown in Figure $5 A$, many glomus cells expressed 5-HT-like immunoreactivity in WT but not in Pet-1 ${ }^{-/-}$mice. Functional analysis of carotid body activity showed that sLTF was absent in both control WT and Pet- $1^{-1-}$ mice reared under normoxia. However, following CIH, sLTF could readily be elicited only in WT but not in Pet $-1^{-/-}$mice (Fig. 5B,C).

To assess whether NOX activation and sLTF require activation of $5-\mathrm{HT}_{2}$ receptors and $\mathrm{PKC}$, carotid bodies harvested from $\mathrm{CIH}$ - and normoxia-treated rats were challenged with 10 episodes of repetitive hypoxia and levels of phosphorylated MARCKS (myristoylated alanine-rich C kinase substrate) were monitored as an index of PKC activation (Wen et al. 2006). Repetitive hypoxia increased p-MARCKS levels by $\sim 3$-fold in $\mathrm{CIH}$-treated but not in control carotid bodies (Fig. 6A). Either blockade of $5-\mathrm{HT}_{2}$ receptors by ketanserin or inhibition of PKC-isoforms with Bis-1 prevented repetitive hypoxia elicited increases in p-MARCKS levels as well as NOX activation in $\mathrm{CIH}$-treated carotid bodies (Fig. 6A,B). More importantly, both ketanserin and Bis-1 also prevented sLTF (Fig. 7). Ketanserin, however, had no effect on 
dopamine $(100 \mu \mathrm{M})$ evoked sensory inhibition of the carotid body (data not shown), suggesting that at $1 \mu \mathrm{M}$ concentration, it selectively affected 5-HT receptors.

\section{ROS generated by NOX mediates IH-} induced SLTF of the carotid body NOX activation leads to generation of ROS, especially $\mathrm{O}_{2}{ }^{-}$. To determine whether $\mathrm{O}_{2} \cdot{ }^{-}$generated by NOX contributes to sLTF, the effect of MnTMPyP, a membrane permeable scavenger of $\mathrm{O}_{2}{ }^{-}$ was examined. When $\mathrm{CIH}$-treated carotid bodies were continuously challenged with $50 \mu \mathrm{M}$ MnTMPyP, repetitive hypoxia did not elicit sLTF $(\mathrm{CIH}+\mathrm{Ve}-$ hicle $\mathrm{sLTF}=+160 \pm 11 \%$ vs $\mathrm{CIH}+\mathrm{MnTMPyP}=+18 \pm 8 \% ; p<0.01$; $n=6$ each). However, when applied 15 min after the onset of sLTF, MnTMPyP did not inhibit sLTF (Fig. $8 A, C$ ). To test whether $\mathrm{H}_{2} \mathrm{O}_{2}$, a dismutated product of $\mathrm{O}_{2}{ }^{-}$- contributes to sLTF, carotid bodies were challenged with $200 \mathrm{U} / \mathrm{ml}$ PEGcatalase, a membrane permeable scavenger of $\mathrm{H}_{2} \mathrm{O}_{2} 15 \mathrm{~min}$ after the onset of sLTF. As shown in Figure $8, B$ and $C$, PEG-catalase completely prevented sLTF.

We examined whether priming the carotid body with exogenous $\mathrm{H}_{2} \mathrm{O}_{2}$ can mimic the effects of $\mathrm{CIH}$ in control normoxia-treated carotid bodies. As shown in Figure $9 A$, in presence of as little as $500 \mathrm{nM} \mathrm{H}_{2} \mathrm{O}_{2}$, repetitive hypoxia evoked robust sLTF in normoxia-treated carotid bodies, similar to that seen with $\mathrm{CIH}$ treatment. Control experiments revealed that in the absence of $\mathrm{H}_{2} \mathrm{O}_{2}$, repetitive hypoxia was ineffective in evoking sLTF, and superfusion with $500 \mathrm{nM} \mathrm{H}_{2} \mathrm{O}_{2}$ alone for $90 \mathrm{~min}$ had no effect on the baseline sensory activity (Fig. 9A). Like wise, in presence of 200 nM $\mathrm{H}_{2} \mathrm{O}_{2}$, repetitive hypoxia also evoked sLTF in carotid bodies from control WT and $g p 91^{\text {phox-/Y }}$ as well as Pet-1 $1^{-1-}$ mice reared under normoxia (Fig. 9B).

\section{Discussion}

In the present study, we examined the role of NOX in CIH-evoked sensory plasticity of the carotid body manifested as sLTF. The following lines of evidence demonstrate that NOX is essential for evoking sLTF. First, mRNAs encoding NOX1, 2, 3 and 4 isoforms were expressed, and $\mathrm{CIH}$ upregulated NOX1, 2 and 4 mRNAs as well as corresponding NOX2 and 4 proteins in rat carotid bodies. Second, NOX activity increased in response to repetitive hypoxia in CIH but not in control carotid bodies. Third, three structurally and functionally distinct inhibitors of NOX (i.e., apocynin, DPI, AEBFS) prevented sLTF.
A
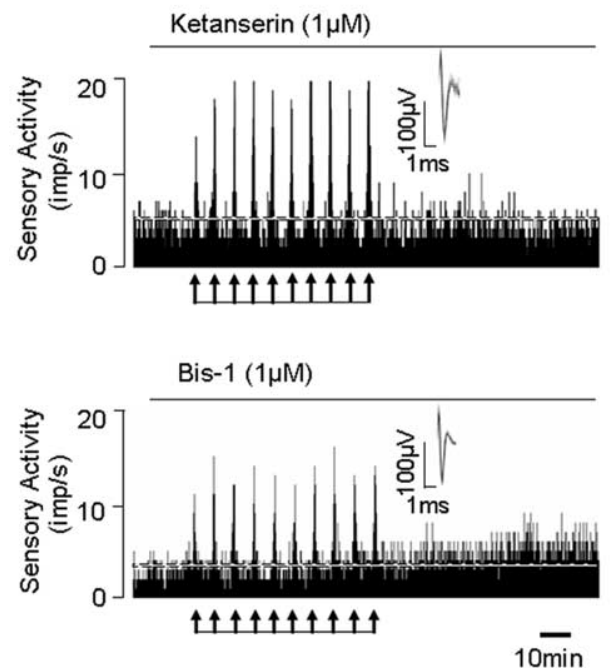

B

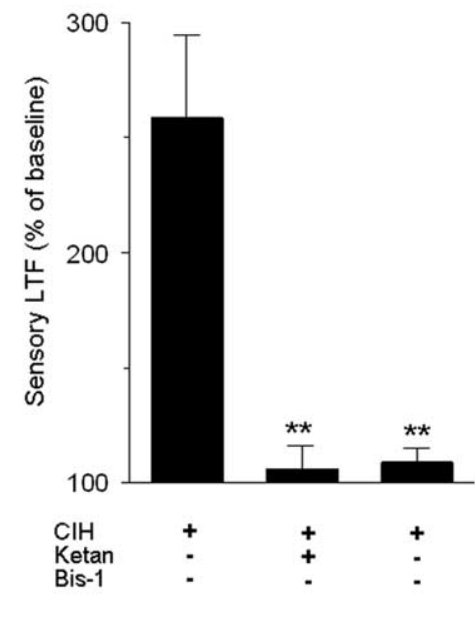

Figure 7. $5-\mathrm{HT}_{2}$ receptor antagonist and PKC inhibitor prevent $\mathrm{L} \mathrm{TF}$ of the carotid body. $\boldsymbol{A}$, Examples of the effects of repetitive hypoxia (at arrows) on sensory activity of (IH-treated rat carotid bodies in the presence of $1 \mu \mathrm{m}$ ketanserin (top) or $1 \mu \mathrm{m}$ Bis-1 (bottom). Superimposed action potentials of a single fiber from which the data were derived are shown in the insets. Note that ketanserin and Bis-1 prevented repetitive hypoxia-evoked sLTF. imp, Impulses. $\boldsymbol{B}$, Average data showing the absence of sLTFin presence of ketanserin or Bis-1. Data presented are mean \pm SEM from CIH carotid bodies treated with vehicle $(n=7)$, or in presence of $1 \mu \mathrm{m}$ ketanserin $(n=6)$ or $1 \mu \mathrm{m}$ Bis-1 $(n=6) .{ }^{* *} p<0.01$ compared with ClH-exposed carotid bodies. Ketan, Ketanserin.
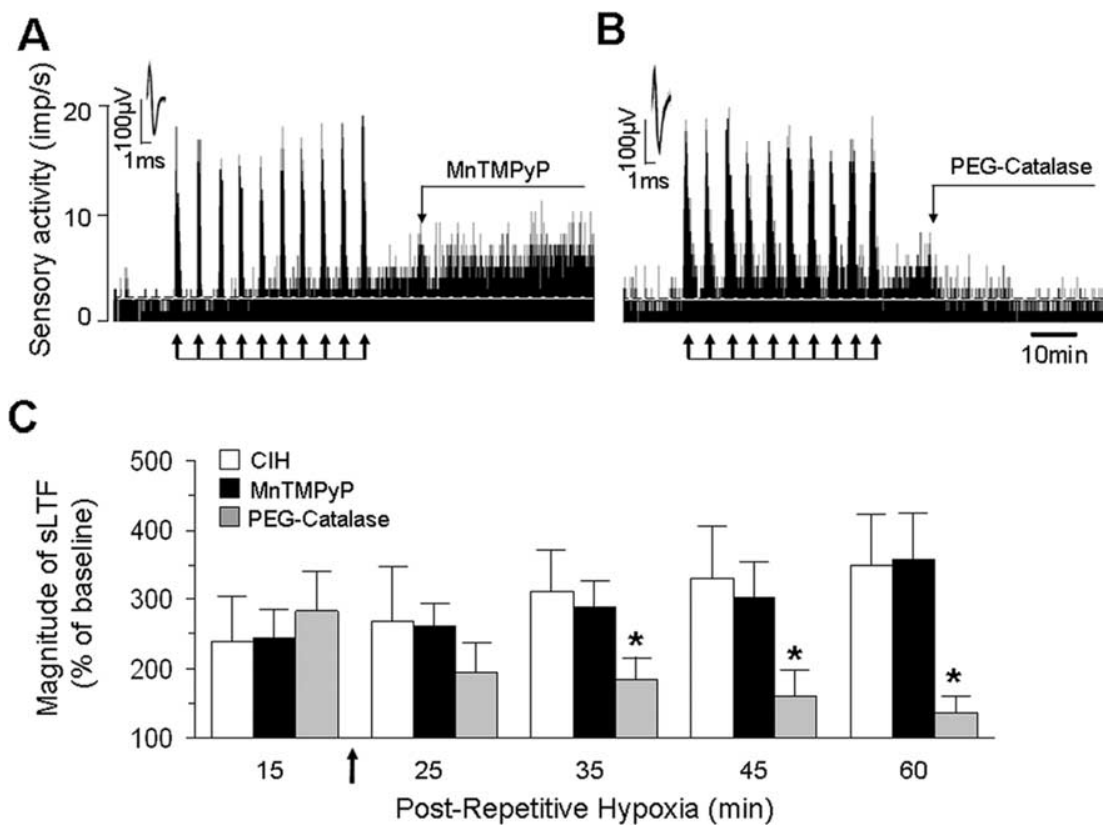

Figure 8. $\mathrm{H}_{2} \mathrm{O}_{2}$ mediates $S L T F$ of the rat carotid bodies. $A, B$, Examples of ClH-treated rat carotid body sensory response to repetitive hypoxia (at arrows) in the presence of MnTMPyP $(50 \mu \mathrm{m} ; \boldsymbol{A})$ or PEG-catalase $(200 \mathrm{U} / \mathrm{ml} ; \boldsymbol{B})$. Superimposed action potentials of a single fiber from which the data were derived are shown in the insets. imp, Impulses. $\boldsymbol{C}$, Average data of the magnitude of sLTF during the 15th, 25th, 35th, 45th, and 60th minute of postrepetitive hypoxia period in presence of vehicle (open columns, $n=6$ ), $50 \mu \mathrm{m}$ MnTMPyP (filled columns, $n=6$ ), or PEG-catalase (200U/ml; gray columns, $n=6$ ). MnTMPyP or PEG catalase was added during postrepetitive hypoxia as indicated by arrow. PEG-catalase but not MnTMPyP prevented sLTF. ${ }^{*} p<0.05$ compared with vehicle-treated $\mathrm{ClH}$ carotid bodies.

Although CIH upregulated three NOX isoforms, sLTF was absent in $g p 91^{\text {phox }}$ knock-out mice, suggesting a major role for NOX2 in mediating sensory plasticity of the carotid body, which was further supported by the observation that it is primarily localized to the cytoplasm of glomus cells, the putative hypoxia 
A
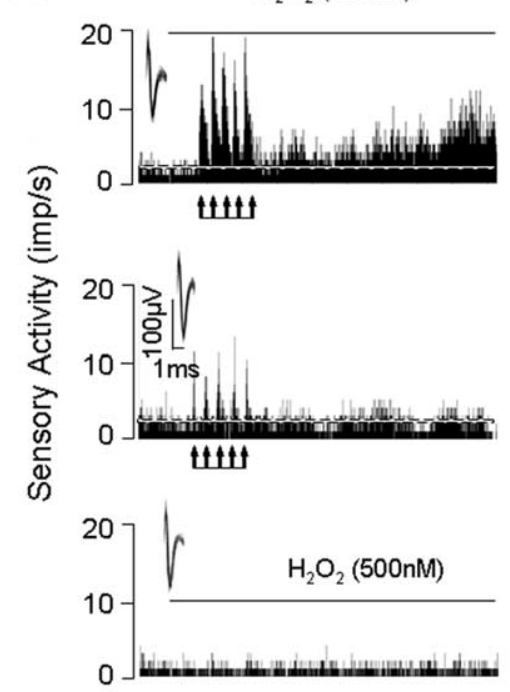

B
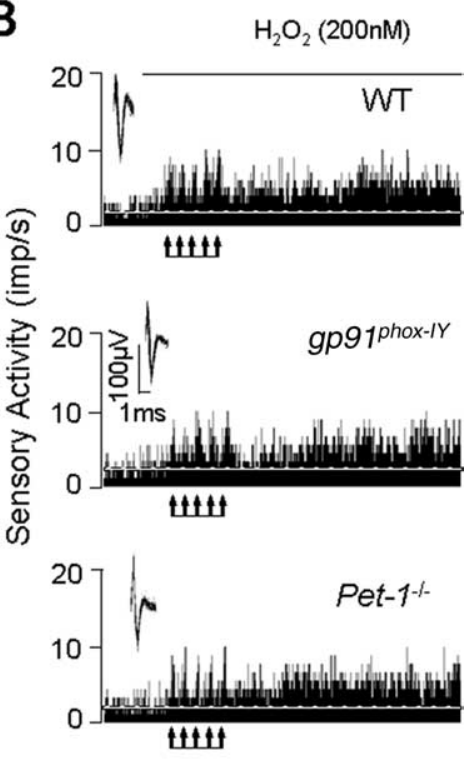

Figure 9. Priming the carotid bodies with $\mathrm{H}_{2} \mathrm{O}_{2}$ evokes sLTF. A, Examples of the effects repetitive hypoxia (at arrows) on sensory activity of the carotid bodies from rats reared under normoxia in the presence (top) or in the absence (middle) of $500 \mathrm{~nm}$ $\mathrm{H}_{2} \mathrm{O}_{2}$. Note sLTF in the presence but not in the absence of $\mathrm{H}_{2} \mathrm{O}_{2}$. Continuous exposure with $500 \mathrm{~nm} \mathrm{H}_{2} \mathrm{O}_{2}$ for 90 min had no effect on baseline sensory activity of the carotid body (bottom). Superimposed action potentials of a single fiber from which the data were derived are shown in the insets. $\boldsymbol{B}$, Examples of the effects repetitive hypoxia (at arrows) on sensory activity of the carotid bodies from WT (top), gp $97^{\text {phox }-Y}$ (middle), and Pet- $1^{-1-}$ (bottom) mice in the presence of $200 \mathrm{~nm} \mathrm{H}_{2} \mathrm{O}_{2}$. Note that priming with $\mathrm{H}_{2} \mathrm{O}_{2}$ evoked sLTF in all three mice. imp, Impulses.

\section{$\mathrm{CIH}$}<smiles>[3H]I</smiles>

\section{$\mathrm{Ca}^{2+}$ mobilization}<smiles>[AlH2]</smiles>

5-HT release

$5-\mathrm{HT}_{2} \underset{\downarrow}{\downarrow}$ receptor activation

PKC activation

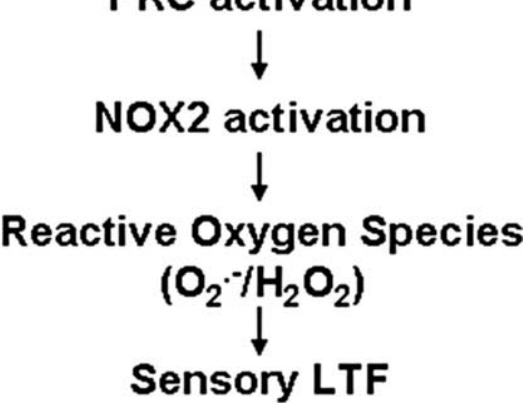

Figure 10. Schematic presentation of $5-H T$ and NOX signaling cascade mediating sLTF of the CIH-treated carotid bodies.

sensing cells. In contrast, NOX4 expression was ubiquitous and was confined to the nucleus rather than the cytoplasm. Nuclear localization of NOX4 was also recently reported in cells of pulmonary origin (Pendyala et al. 2009). NOX 4, because of its nuclear localization, might play a role in $\mathrm{CIH}$-evoked transcriptional activation (Yuan et al. 2008), rather than evoking sLTF, a possibility that requires further investigation. Since NOX1 is a homolog of NOX2 (Suh et al. 1999; Bánfi et al. 2000), it might also contribute to sLTF similar to NOX2. It has been proposed that NOX2 functions as an $\mathrm{O}_{2}$ sensor in the carotid body (see Dinger et al., 2007 for references). However, consistent with a previous report $(\mathrm{He}$ et al. 2002), we also found that carotid body sensory response to acute hypoxia was preserved in NOX-2 knock-out mice. These findings taken together suggest a novel role for NOX2 in inducing sensory plasticity of the carotid body under the conditions such as $\mathrm{CIH}$, rather than functioning as an $\mathrm{O}_{2}$ sensor.

Despite the upregulation of NOX2 protein by CIH, basal NOX activity was nearly the same as in controls; whereas it could be activated only after acute repetitive hypoxia, suggesting that $\mathrm{CIH}$ leads to a regulated rather than constitutive activation of NOX. The following observations demonstrate that $5-\mathrm{HT}_{2}$ receptors coupled to $\mathrm{PKC}$ activation contribute to the regulated NOX activation. First, 5- $\mathrm{HT}_{2}$ receptor antagonist as well as $\mathrm{PKC}$ inhibitor prevented NOX activation in CIH-treated carotid bodies. Second, repetitive hypoxia led to PKC activation in CIH but not in control carotid bodies and a $5-\mathrm{HT}_{2}$ receptor antagonist prevented this effect. Activation of $5-\mathrm{HT}_{2}$ receptors require release of $5-\mathrm{HT}$. Indeed, hypoxia evoked robust 5-HT release from $\mathrm{CIH}$ but not from control carotid bodies. More importantly, sLTF, which is the consequence of NOX activation by $5-\mathrm{HT}_{2}$ receptors, was completely absent in Pet- $1^{-1-}$ mice with impaired 5-HT expression in the carotid body. A recent study reported that exogenous 5-HT is a potent inducer of sLTF in control rat carotid bodies, and the effects of 5 -HT are mediated via NOX activation by $5-\mathrm{HT}_{2}$ receptors and PKC (Peng et al. 2006a). These findings taken together with the observations of the present study suggest that 5-HT via $5-\mathrm{HT}_{2}$ receptor activation mediates regulated NOX2 activation and the ensuing sLTF in CIH-treated carotid bodies.

It is intriguing that hypoxia released 5-HT from $\mathrm{CIH}$ but not from control carotid bodies. Considerable evidence suggests that activation of voltage-gated $\mathrm{Ca}^{2+}$ channels and subsequent elevations in $\left[\mathrm{Ca}^{2+}\right]_{\mathrm{i}}$ in glomus cells are critical for hypoxia-evoked transmitter release from the carotid body [see Prabhakar (2000) for references]. However, $\mathrm{CdCl}_{2}$, a broad spectrum voltage-gated $\mathrm{Ca}^{2+}$ channel blocker had no effect; whereas 2-APB, a purported blocker of IP-3 receptors and/or TRPM2 channels completely prevented hypoxia-evoked 5-HT release from $\mathrm{CIH}$-treated carotid bodies. These findings indicate that $\mathrm{CIH}$ recruits additional $\mathrm{Ca}^{2+}$ signaling pathways such as mobilization of intracellular $\mathrm{Ca}^{2+}$ for evoking 5-HT release by hypoxia. The absence of NOX activation and SLTF in carotid bodies reared under normoxia is conceivably be due to the inability of hypoxia to release 5-HT, which is necessary for NOX activation.

The finding that $\mathrm{O}_{2} \cdot{ }^{-}$generated by NOX mediates LTP in the CNS (Kishida and Klann, 2007) prompted us to investigate whether it also contributes to sLTF in the carotid body. The observations that MnTMPyP, a scavenger of $\mathrm{O}_{2}{ }^{-}{ }^{-}$was effective only when given before the onset, whereas PEG-catalase, a scavenger 
of $\mathrm{H}_{2} \mathrm{O}_{2}$ prevented sLTF although given after its onset suggest that $\mathrm{H}_{2} \mathrm{O}_{2}$ generated from $\mathrm{O}_{2}{ }^{-}$- contributes to sLTF. Furthermore, priming the carotid bodies from control normoxic rats with nanomolar concentrations of exogenous $\mathrm{H}_{2} \mathrm{O}_{2}$ mimicked the effects of CIH by evoking sLTF. Although $\mathrm{CIH}$ was ineffective in eliciting sLTF in $g p 91^{p h o x-/ Y}$ and Pet-1 ${ }^{-1-}$ mice, priming with exogenous $\mathrm{H}_{2} \mathrm{O}_{2}$ elicited sLTF by repetitive hypoxia in both groups of mice indicating that $\mathrm{H}_{2} \mathrm{O}_{2}$ is downstream to $5-\mathrm{HT}$ dependent NOX2 activation. The signaling cascade leading to $\mathrm{CIH}$-induced NOX activation and the ensuing sLTF identified in this study is summarized in Figure 10.

What might be the functional significance of $\mathrm{CIH}$-induced sLTF of the carotid body? Sleep disordered breathing is characterized by transient repetitive cessations of breathing (apneas) and leads to periodic decreases in arterial $\mathrm{pO}_{2}$ or $\mathrm{CIH}$. Individuals affected by recurrent apneas have increased risk for developing several cardio-respiratory comorbidities including increased sympathetic tone and respiratory abnormalities (Shahar et al. 2001). The augmented carotid body afferent activity triggers reflex activation of sympathetic nervous system and breathing. Therefore, it is conceivable that CIH-evoked sLTF of the carotid body via ROS generated by 5 -HT-NOX2 signaling contributes to the autonomic morbidities associated with recurrent apneas.

\section{References}

Baker TL, Fuller DD, Zabka AG, Mitchell GS (2001) Respiratory plasticity: differential actions of continuous and episodic hypoxia and hypercapnia. Respir Physiol 129:25-35.

Bánfi B, Maturana A, Jaconi S, Arnaudeau S, Laforge T, Sinha B, Ligeti E, Demaurex N, Krause KH (2000) A mammalian H+ channel generated through alternative splicing of the NADPH oxidase homolog NOH-1. Science 287:138-142.

Bedard K, Krause KH (2007) The NOX family of ROS-generating NADPH oxidases: physiology and pathophysiology. Physiol Rev 87:245-313.

Dinger B, He L, Chen J, Liu X, Gonzalez C, Obeso A, Sanders K, Hoidal J, Stensaas L, Fidone S (2007) The role of NADPH oxidase in carotid body arterial chemoreceptors. Respir Physiol Neurobiol 157:45-54.

He L, Chen J, Dinger B, Sanders K, Sundar K, Hoidal J, Fidone S (2002) Characteristics of carotid body chemosensitivity in NADPH oxidasedeficient mice. Am J Physiol Cell Physiol 282:C27-C33.

Hendricks T, Francis N, Fyodorov D, Deneris ES (1999) The ETS domain factor Pet-1 is an early and precise marker of central serotonin neurons and interacts with a conserved element in serotonergic genes. J Neurosci 19:10348-10356.

Hendricks TJ, Fyodorov DV, Wegman LJ, Lelutiu NB, Pehek EA, Yamamoto B, Silver J, Weeber EJ, Sweatt JD, Deneris ES (2003) Pet-1 ETS gene plays a critical role in 5-HT neuron development and is required for normal anxiety-like and aggressive behavior. Neuron 37:233-247.

Jacono FJ, Peng YJ, Kumar GK, Prabhakar NR (2005) Modulation of the hypoxic sensory response of the carotid body by 5-hydroxytryptamine: role of the 5-HT2 receptor. Respir Physiol Neurobiol 145:135-142.
Kishida KT, Klann E (2007) Sources and targets of reactive oxygen species in synaptic plasticity and memory. Antioxid Redox Signal 9:233-244.

Kishida KT, Hoeffer CA, Hu D, Pao M, Holland SM, Klann E (2006) Synaptic plasticity deficits and mild memory impairments in mouse models of chronic granulomatous disease. Mol Cell Biol 26:5908-5920.

Mayo LA, Curnutte JT (1990) Kinetic microplate assay for superoxide production by neutrophils and other phagocytic cells. Methods Enzymol 186:567-575.

Pendyala S, Gorshkova IA, Usatyuk P, He D, Pennathur A, Lambeth JD, Thannickal VJ, Natarajan V (2009) Role of NOX4 and NOX2 in hyperoxia-induced reactive oxygen species generation and migration of human lung endothelial cells. Antioxid Redox Signal 11:1-18.

Peng YJ, Prabhakar NR (2004) Effect of two paradigms of chronic intermittent hypoxia on carotid body sensory activity. J Appl Physiol 96:1236-1242.

Peng YJ, Overholt JL, Kline D, Kumar GK, Prabhakar NR (2003) Induction of sensory long-term facilitation in the carotid body by intermittent hypoxia: implications for recurrent apneas. Proc Natl Acad Sci U S A 100:10073-10078.

Peng YJ, Yuan G, Jacono FJ, Kumar GK, Prabhakar NR (2006a) 5-HT evokes sensory long-term facilitation of rodent carotid body via activation of NADPH oxidase. J Physiol 576:289-295.

Peng YJ, Yuan G, Ramakrishnan D, Sharma SD, Bosch-Marce M, Kumar GK, Semenza GL, Prabhakar NR (2006b) Heterozygous HIF-1alpha deficiency impairs carotid body-mediated systemic responses and reactive oxygen species generation in mice exposed to intermittent hypoxia. J Physiol 577:705-716.

Pinilla PJ, Hernández AT, Camello MC, Pozo MJ, Toescu EC, Camello PJ (2005) Non-stimulated $\mathrm{Ca}^{2+}$ leak pathway in cerebellar granule neurones. Biochem Pharmacol 70:786-793.

Powell FL, Milsom WK, Mitchell GS (1998) Time domains of the hypoxic ventilatory response. Respir Physiol 112:123-134.

Prabhakar NR (2000) Oxygen sensing by the carotid body chemoreceptors. J Appl Physiol 88:2287-2295.

Shahar E, Whitney CW, Redline S, Lee ET, Newman AB, Javier Nieto F, O'Connor GT, Boland LL, Schwartz JE, Samet JM (2001) Sleepdisordered breathing and cardiovascular disease: cross-sectional results of the Sleep Heart Health Study. Am J Respir Crit Care Med 163:19-25.

Suh YA, Arnold RS, Lassegue B, Shi J, Xu X, Sorescu D, Chung AB, Griendling KK, Lambeth JD (1999) Cell transformation by the superoxidegenerating oxidase Mox1. Nature 401:79-82.

Wen Y, Gu J, Li SL, Reddy MA, Natarajan R, Nadler JL (2006) Elevated glucose and diabetes promote interleukin-12 cytokine gene expression in mouse macrophages. Endocrinology 147:2518-2525.

Youngson C, Nurse C, Yeger H, Curnutte JT, Vollmer C, Wong V, Cutz E (1997) Immunocytochemical localization on $\mathrm{O}_{2}$-sensing protein (NADPH oxidase) in chemoreceptor cells. Microsc Res Tech 37:101-106.

Yuan G, Nanduri J, Khan S, Semenza GL, Prabhakar NR (2008) Induction of HIF-lalpha expression by intermittent hypoxia: Involvement of NADPH oxidase, $\mathrm{Ca}^{2+}$ signaling, prolyl hydroxylases, and mTOR. J Cell Physiol 217:674-685.

Zhan G, Serrano F, Fenik P, Hsu R, Kong L, Pratico D, Klann E, Veasey SC (2005) NADPH oxidase mediates hypersomnolence and brain oxidative injury in a murine model of sleep apnea. Am J Respir Crit Care Med 172:921-929. 